\title{
Report on antibiotic sensitivity test trial organized by the Bacteriology Committee of the Association of Clinical Pathologists ${ }^{1}$
}

As the result of the antibiotic sensitivity trial organized by the Bacteriological Committee of the Association of Clinical Pathologists, in which 154 laboratories took part, the following recommendations were approved:-

1 Zone readings should always be compared with a control sensitive strain, preferably on the same culture but at least on the same medium incubated at the same time.

2 Inoculum difference between control and test must be taken into account and the test repeated when in doubt.

3 Medium containing blood (10\% in layered plates, $5 \%$ in non-layered) and no added carbohydrate should be used for all tests whether the organism is fastidious or not.

4 Direct inoculation of the specimen is recommended, although in heavy mixed culture and when growth of a potential pathogen is too scanty for a zone to be formed, tests will have to be repeated.

5 Tests against toxic drugs should not be routinely reported.

6 Results of sensitivity tests on commensal organisms should not be reported.

7 Tests on several antibiotics of the same group are very seldom necessary.

Laboratories were invited to take part in a check of antibiotic sensitivity test methods. One hundred and fifty-seven responded and apologies are due to three laboratories which were accidentally omitted.

In order to check results as closely as possible, the strains sent out were freshly isolated from patients with a clear-cut history of acute infection in whom the results of treatment were known. They were sent in the form of specimens to simulate closely natural working conditions and each laboratory was asked to test them by their usual routine method.

The laboratories were told the source of the specimen and also that the patients had not recently received antibiotic treatment so that an extensive range of tests employing new drugs was not required.

A questionnaire was included so that the type of medium, mode of innoculation, and antibiotic preparations used were known. Also the laboratory was asked what zones a control sensitive organism could be expected to show by their method, and whether controls were routinely tested.

In order to check the test strains sent by the Secretary of the Bacteriology Committee from University College Hospital, London, they were also sent to

\footnotetext{
${ }^{1}$ Committee members: Dr. Joan Taylor (Chairman), Dr. E. J. L. Lowbury, Professor A. C. Cunliffe, Dr. J. A. Dudgeon, Professor Mary Barber (co-opted). Report prepared by Dr. E. Joan Stokes (Secretary).
}

Professor Barber, Hammersmith Hospital, London, prepared in the same way, as specimens. She tested them by the routine method in which drugs are incorporated in ditch plates, whereas at University College Hospital impregnated paper discs are employed. In spite of these totally different routine techniques, results in the two laboratories proved to be the same with two minor variations. The agreed results are seen in Table $I$.

In all four cases the result of treatment of the patient was what would be expected in view of the laboratory test result. In two cases the organisms were sensitive and treatment was successful at the first attempt. In one case, with Proteus infection, nitrofurantoin was tried empirically without success, followed by ampicillin which proved effective. In another case, a staphylococcal abscess caused by the penicillinase-producing strain 1 , treatment with penicillin had no effect, but recovery could not be attributed to a change of drug since the abscess was opened when treatment was changed to tetracycline.

All the 'specimens' were prepared from a single batch of cultures so that all were comparable. The staphylococci were sent in Stewart's transport medium, the swab having been dipped in a suitably diluted overnight broth culture with human plasma added. The bacilli were sent as overnight peptone water cultures suitably diluted in normal autoclaved 
urine. Variation which might occur in the post was checked by posting specimens back to University College Hospital for retesting. Since the specimens were sent at the end of January, growth in the post was not very likely, but one laboratory was in Norway and one in East Africa. Laboratories were asked to return all specimens after sampling so that survival in the post from long distances could be checked. All specimens sent back from laboratories giving erroneous results were retested by the University College Hospital routine method. Strains 1,2 , and 4 survived well and their antibiotic sensitivity was unaltered. Strain 3, Proteus mirabilis, did not survive well. Only specimens returned within a few days were viable and could be retested; antibiotic sensitivity had not changed during this time.

There is little doubt therefore that when a laboratory reported one of these strains resistant or sensitive, when Hammersmith Hospital, University College Hospital (and the majority of other laboratories) found the reverse result, the report was erroneous. Minor variations, e.g., 'moderately sensitive', when the strain was either sensitive or resistant, were disregarded.

\section{RESULTS}

Tables I and II show the sensitivity results of the four strains and the number of laboratories sending false reports; almost half sent at least one false result. Table II shows a further analysis of the errors, and Table IIb relates them to the individual strains.

Of the drugs tested, sulphonamide gave the greatest number of errors, and, because tests are notoriously difficult, nine laboratories in the trial made no attempt to include them. Penicillin and ampicillin come next on the list. Penicillinase producers which do not produce enough of the
TABLE II

NUMBER OF LABORATORIES SENDING FALSE REPORTS

$\begin{array}{lc}\text { Total taking part in trial } & 154 \\ \text { No errors } & 82 \\ \text { At least } 1 \text { error } & 72 \\ & 39 \text { (19 sulphonamide) } \\ 1 \text { error reported } & 26 \\ 2 \text { errors reported } & 5 \\ 3 \text { errors reported } & 2\end{array}$

TABLE IIa

ANALYSIS OF ERRORS

\begin{tabular}{|c|c|c|c|c|c|}
\hline \multirow[b]{2}{*}{ Antibiotic } & \multicolumn{3}{|c|}{ 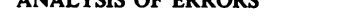 } & \multirow{2}{*}{\multicolumn{2}{|c|}{$\begin{array}{l}\text { False } \\
\text { Sensitivity }\end{array}$}} \\
\hline & $\begin{array}{l}\text { Total } \\
\text { Tests }\end{array}$ & $\begin{array}{l}\text { Total } \\
\text { Errors }\end{array}$ & $\begin{array}{l}\text { False } \\
\text { Resistance }\end{array}$ & & \\
\hline Penicillin & 407 & 21 & $\mathbf{0}$ & 21 & \\
\hline Ampicillin & 221 & 14 & 11 & 3 & \\
\hline Sulphonamide & 436 & 41 & 41 & 0 & \\
\hline Tetracycline & 552 & 1 & $\mathbf{0}$ & 1 & \\
\hline Streptomycin & 293 & 7 & 7 & 0 & \\
\hline Erythromycin & 545 & 2 & 1 & 1 & \\
\hline Chloramphenicol & 488 & 9 & 9 & 0 & \\
\hline Nitrofurantoin & 258 & 14 & 4 & 10 & \\
\hline Neomycin & 62 & 1 & 1 & $\mathbf{0}$ & \\
\hline Kanamycin & 97 & 3 & 3 & 0 & \\
\hline Polymyxin & 27 & 1 & $\mathbf{0}$ & 1 & - \\
\hline Totals & 3,386 & 114 & 77 & 37 & $\underline{\underline{z}}$ \\
\hline
\end{tabular}

enzyme under test conditions to neutralize all the penicillin diffused from the disc may be reported sensitive. The 21 laboratories sending false reports did not recognize any difference in penicillin sensi tivity between the two strains of staphylococci sent to them. It should be noted that even when a zone is seen, the size of the colonies at its edge, and the lack of lysis in this area are easily observed, anc there should have been no difficulty in recognizing these strains. When cultures are compared with sensitive control the difference is, of course, muct more obvious.

It is clear that with the exception of penicillin resistance is much more often falsely reported than sensitivity. When penicillin is excluded and also sulphonamide, which might unduly weight the errors

TABLE I

RESULT OF ROUTINE ANTIBIOTIC SENSITIVITY TESTS ON FOUR STRAINS SENT AS SPECIMENS ${ }^{1}$

'Specimen'

Antibiotic

Penicillin Ampi- Cloxa- Sulphon-Tetra- Erythro-Strepto- Neo- Kana- Chlor- Novo- Nitrocillin cillin amide cycline mycin mycin mycin mycin ampheni-biocin furantoin col

\begin{tabular}{|c|c|c|c|c|}
\hline $\begin{array}{l}\text { Abscess behind ear } \\
\text { Staph. aureus (penicillinase } \\
\text { producer) }\end{array}$ & $-^{*}$ & - & + & + \\
\hline $\begin{array}{l}\text { Carbuncle of the neck } \\
\text { Staph aureus }\end{array}$ & $t^{*}$ & + & + & + \\
\hline $\begin{array}{l}\text { Infected urine } \\
\text { Proteus mirabilis }\end{array}$ & & $+^{*}$ & & \pm \\
\hline $\begin{array}{l}\text { Infected urine } \\
\text { E. coli }\end{array}$ & + & \pm & & $+^{*}$ \\
\hline
\end{tabular}

${ }^{1}$ Agar diffusion methods with control sensitive organism at Hammersmith and U.C.H. laboratories.

* = Confirmed by clinical response

$+=$ zone at least as large as control

$士=$ zone less than control (at least $3 \mathrm{~mm}$. smaller, inoculum being equivalent; sensitive control zone $=10-15 \mathrm{~mm}$.)

- = no zone 
TABLE IIb

ERRORS RELATED TO STRAINS TESTED

\begin{tabular}{|c|c|c|c|c|}
\hline Antibiotic & $\begin{array}{l}\text { Staph. aureus } I \\
\text { (Penicillinase Producer) }\end{array}$ & $\begin{array}{l}\text { Staph. aureus } 2 \\
\text { (Sensitive to All } \\
\text { Common Drugs) }\end{array}$ & Proteus mirabilis & E. coli \\
\hline $\begin{array}{l}\text { Penicillin } \\
\text { Ampicillin } \\
\text { Sulphonamide } \\
\text { Tetracycline } \\
\text { Streptomycin } \\
\text { Erythromycin } \\
\text { Chloramphenicol } \\
\text { Nitrofurantoin } \\
\text { Neomycin } \\
\text { Kanamycin } \\
\text { Polymyxin }\end{array}$ & $\begin{array}{l}21 \mathrm{~S} \\
3 \mathrm{~S} \\
\text { Not recorded } \\
0 \\
0 \\
1 \mathrm{R} \\
1 \mathrm{R} \\
\text { Not tested } \\
0 \\
\text { Not tested } \\
\text { Not tested }\end{array}$ & $\begin{array}{l}0 \\
0 \\
\text { Not recorded } \\
0 \\
2 R \\
0 \\
1 R \\
\text { Not tested } \\
1 R \\
\text { Not tested } \\
\text { Not tested }\end{array}$ & $\begin{array}{l}0 \\
11 \mathrm{R} \\
0 \\
1 \mathrm{~S} \\
3 \mathrm{R} \\
0 \\
6 \mathrm{R} \\
10 \mathrm{~S} \\
0 \\
2 \mathrm{R} \\
\text { IS }\end{array}$ & $\begin{array}{l}0 \\
0 \\
41 R \\
0 \\
2 R \\
1 S \\
1 R \\
4 R \\
0 \\
1 R \\
0\end{array}$ \\
\hline
\end{tabular}

$\mathbf{R}=$ resistance falsely reported.

$\mathrm{S}=$ sensitivity falsely reported.

on the resistance side, there are 36 false resistance reports and 16 false sensitivity reports.

Tests with Proteus and ampicillin proved difficult to read. In the experience of the assessors this is often due to much too heavy an inoculum or to reading the zone of the spreading edge, rather than the zone of inhibition of colonies. Colony zones are much more comparable with titration results and with the results of treatment. The only other drug which proved difficult to test was nitrofurantoin, the Proteus being rather surprisingly reported falsely sensitive on 10 occasions. The cause for this would have remained obscure had not Dr. Jane Fullerton, whose laboratory was one of the 10 reporting false sensitivity, noticed different results with a strain of coli when tested on two different batches of Oxoid sensitivity-test agar, CM 215 and CM 261. The difference between these media is that 215 contains more glucose than 261 . She sent her two batches of media, discs, and coli, to University College Hospital for investigation. Her results were confirmed and three strains were further investigated with the results seen in Table III. In addition, the strains were tested on nutrient agar plates without glucose at $p \mathrm{H} 6$,

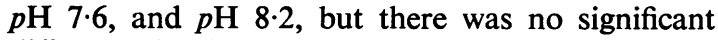
difference in the zones on these three media. The effect of glucose could not be demonstrated by tube titration. Further investigation is required, but in the meantime addition of blood to the medium reduces the effect considerably and medium without glucose or other added carbohydrate is to be preferred for sensitivity tests. (Jewell \& Pearmain's medium quoted in the Oxoid catalogue contains no glucose.)

ANTIBIOTIC PREPARATION There seems to be little correlation between the errors and the antibiotic paper disc preparation employed (Table IV). The errors for those using tablets is considerably higher, but the number of laboratories using them is much smaller. Storage methods in the laboratory may be at fault, but no strength of antibiotic is stated by the manufacturer so that it seems likely that the tablets are more variable than paper discs.

\section{TABLE IV}

ERRORS RELATED TO ANTIBIOTIC PREPARATION USED

\begin{tabular}{llll} 
No. of Laboratories & $\begin{array}{l}\text { Mainly } \\
\text { Multodisk }\end{array}$ & Discs Only & Tablets Only \\
\hline Total & 66 & 44 & \\
Correct & 38 & 27 & 24 \\
At least 1 error & 28 & 17 & 6 \\
At least 1 error & $11(16.6 \%)$ & $7(16 \%)$ & $10(41.6 \%)$ \\
(excluding penicillin, & & &
\end{tabular}

sulphonamide, nitrofurantoin

\begin{tabular}{|c|c|c|c|c|c|c|}
\hline \multirow[b]{2}{*}{ Media } & \multicolumn{2}{|l|}{ Experiment 1} & \multicolumn{2}{|l|}{ Experiment 2} & \multicolumn{2}{|l|}{ Experiment 3} \\
\hline & $\begin{array}{l}\text { Oxford } \\
\text { Staphylococcus } \\
\text { Control } \\
\text { (zones in } \mathrm{mm} . \text { ) }\end{array}$ & $\begin{array}{l}\text { Proteus A.C.P. } \\
\text { Trial } \\
\text { (zones in mm.) }\end{array}$ & $\begin{array}{l}\text { Oxford } \\
\text { Staphylococcus } \\
\text { Control } \\
\text { (zones in } \mathrm{mm} . \text { ) }\end{array}$ & $\begin{array}{l}\text { Proteus U.C.H. } \\
\text { (zones in mm.) }\end{array}$ & $\begin{array}{l}\text { Oxford } \\
\text { Staphylococcus } \\
\text { Control } \\
\text { (zones in } \mathrm{mm} . \text { ) }\end{array}$ & $\begin{array}{l}\text { Coli } \\
\text { (Fullerton) } \\
\text { (zones in mm.) }\end{array}$ \\
\hline $\begin{array}{l}\text { Nutrient agar }+1 \% \text { glucose } \\
\text { (Oxoid CM 215) }\end{array}$ & 12 & 3 & 12 & 10 & 11 & 8 \\
\hline Oxoid CM $215+$ blood $10 \%$ & 11 & 0 & 8 & 3 & $12(13)^{1}$ & $9(11)$ \\
\hline $\begin{array}{l}\text { Nutrient agar }+0.2 \% \text { glucose } \\
\text { (Oxoid CM 261) }\end{array}$ & 11 & 0 & 12 & 0 & 11 & 0 \\
\hline $\begin{array}{l}\text { Oxoid CM } 261+\text { blood } 10 \% \\
\text { U.C.H. blood agar }\end{array}$ & $\begin{array}{l}12 \\
10\end{array}$ & $\begin{array}{l}\mathbf{0} \\
\mathbf{0}\end{array}$ & $\begin{array}{l}10 \\
11\end{array}$ & $\begin{array}{l}\mathbf{0} \\
\mathbf{0}\end{array}$ & $\begin{array}{r}9(11) \\
11(11)\end{array}$ & $\begin{array}{l}6(9) \\
8(8)\end{array}$ \\
\hline
\end{tabular}

TABLE III

NITROFURANTOIN SENSITIVITY TESTS ON DIFFERENT MEDIA 

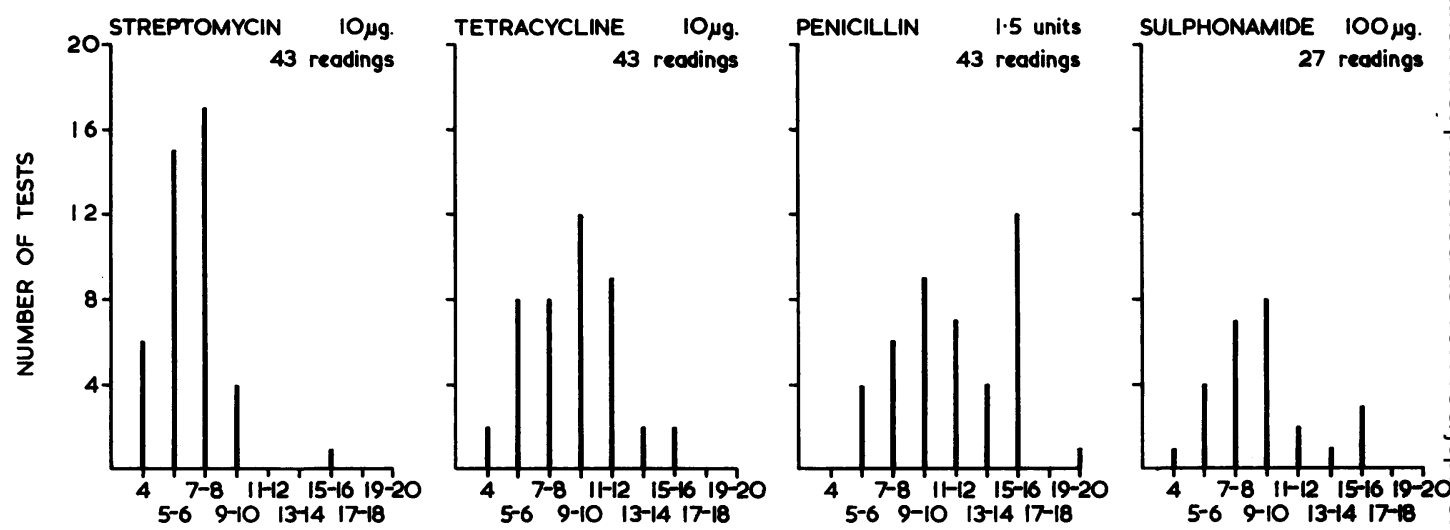

RADIUS ZONE OF INHIBITION (mm.)

FIG. 1. Scatter of inhibition zone readings given by 'sensitive' organisms in 43 different laboratories using Oxoid Multog disks of the same strength.

Forty-three laboratories employing Multodisks (Oxoid) used the same concentrations of each of four drugs but different media, methods of inoculation, and people reading the results. Figure 1 shows the zone readings each would expect a sensitive organism to give. The scatter for the different drugs was penicillin $5-20 \mathrm{~mm}$., streptomycin and sulphonamide 4-15 mm., and tetracycline 4-16 mm. In view of the results in general for Multodisks it seems very unlikely that the wide variation is due to difference in the discs.

INOCULATION METHOD It is hard to judge in individual cases whether the inoculum was heavy or light. Presumably a transfer of a single colony with a loop or swab is heavier than flooding with a suspension, but standard suspensions were seldom used. Flooding plates with liquid cultures is probably heaviest of all. The results of errors related to the

TABLE V

ERRORS RELATED TO INOCULATION METHOD

\begin{tabular}{|c|c|c|c|c|}
\hline \multirow[t]{2}{*}{ No. of Laboratories } & \multicolumn{3}{|c|}{ Pure Culture } & \multirow{2}{*}{$\begin{array}{l}\text { Direct } \\
\text { Plating }\end{array}$} \\
\hline & $\begin{array}{l}\text { Colony to } \\
\text { Plate }\end{array}$ & Suspension & $\begin{array}{l}\text { Liquid } \\
\text { Culture }\end{array}$ & \\
\hline $\begin{array}{l}\text { Total } \\
\text { Correct } \\
\text { At least } 1 \text { error }\end{array}$ & $\begin{array}{l}41 \\
18 \\
23(52 \%)\end{array}$ & $\begin{array}{l}43 \\
23 \\
20(45 \%)\end{array}$ & $\begin{array}{l}23 \\
7 \\
16(69 \%)\end{array}$ & $\begin{array}{l}42 \\
32 \\
10(24 \%)\end{array}$ \\
\hline $\begin{array}{l}\text { Penicillin only } \\
\text { Total } \\
\text { At least } 1 \text { error }\end{array}$ & $\begin{array}{l}39 \\
6(15 \%)\end{array}$ & $63(14 \%)$ & $23(9 \%)$ & $\frac{42}{6}(14 \%)$ \\
\hline $\begin{array}{l}\text { Sulphonamide only } \\
\text { Total } \\
\text { At least } 1 \text { error }\end{array}$ & $\begin{array}{l}39 \\
15(38 \%)\end{array}$ & $\begin{array}{l}41 \\
11(27 \%)\end{array}$ & $\begin{array}{l}23 \\
8(35 \%)\end{array}$ & $\begin{array}{l}37 \\
3(8 \%)\end{array}$ \\
\hline
\end{tabular}

various methods bears this out (Table V). In estimating penicillin sensitivity, which is most easily read from a heavy inoculum, liquid culture showed the least number of errors, whereas this method fared worst in sulphonamide tests where light inoculum is essential. In general, those plating the specimen direct gave the best results.

MEDIA The main point shown in Table VI is thas those using blood in the medium fare much better

TABLE VI

ERRORS RELATED TO MEDIA

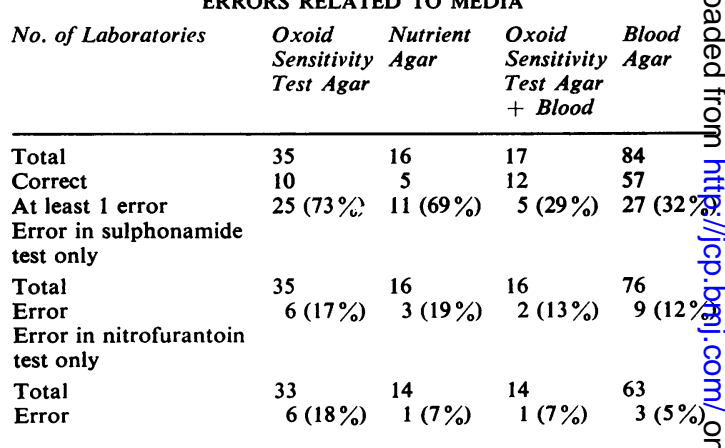

than others. There may be reasons for this other than the medium, because on the whole large departments are better able to insist on the additional expense of using blood routinely. Nevertheless, the need for blood in medium is upheld by the nitrofurantoif results described above.

Probably the most easily comparable inoculation method is direct plating. Table VIa shows results of all those laboratories using this method of inocula tion, which included sulphonamide, penicillin, an nitrofurantoin in the series of drugs tested.

\section{DISCUSSION}

The 'specimens' sent out were simple to test and represent those most frequently encountered hospital laboratories. 
TABLE VIa

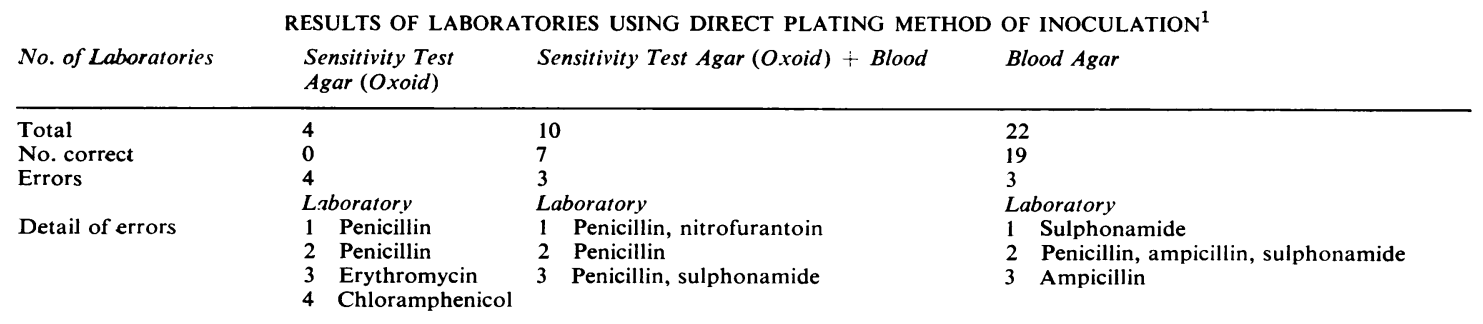

'No laboratory in this group used other nutrient agar without blood.

The results justify complaints from clinicians that laboratory tests, as done at present, are unreliable. This is not surprising in view of the fact that only the two laboratories responsible for checking the results, and two others taking part in the trial, routinely use controls and read their results in comparison with a known sensitive organism, taking inoculum difference into account. Each sensitivity test should be regarded in the light of an experiment. No one would attempt to experiment in a system showing the degree of variability demonstrated in Fig. 1 without proper controls.

Diagnostic laboratories are notoriously overworked. There is good reason therefore to ensure that the work done serves a useful purpose and is not unnecessarily laborious. In this trial many unnecessary tests were done; moreover the method commonly employed of isolating organisms in pure culture, suspending each kind in liquid medium which is then flooded over a plate and tested against six to eight antibiotics, leads in many cases to unnecessary delay in reporting and is unnecessarily laborious.

It is more useful to the clinician to receive the results of four well-controlled tests against drugs chosen as suitable for the type of specimen, which is possible in the majority of cases after overnight incubation, than the results of eight tests uncontrolled a day later. Tests should be made in the first place against antibiotics which are relatively non-toxic unless there is good reason to include new or toxic drugs. Results of sensitivity to toxic drugs such as chloramphenicol, kanamycin, vancomycin, etc., should be reported only when the bacteriologist is specifically recommending them in a difficult case, not routinely. The results of sensitivity tests on commensal organisms should not be reported.

Controlling tests adequately is much less laborious than is often supposed. Provided the control organism is sensitive to the drugs under test and grows at approximately the same rate as the organisms tested it does not matter if it is a different species or grows optimally under different conditions. This means that only two control strains are required. A fully sensitive staphylococcus will suffice for the majority of tests but a coliform is needed for polymyxin and other drugs relatively inactive against staphylococci. An overnight liquid culture of each control diluted to yield an inoculum as nearly as possible equivalent to that of the average specimen will remain stable in the refrigerator throughout the day. Although anaerobic conditions are not optimal for staphylococci they grow almost as rapidly anaerobically, and no special control is required for anaerobes. Slow-growing, non-sporing anaerobes either show no zone at all, or, when they are sensitive, a much wider zone than a control staphylococcus. Equivocal results are seldom seen.

A serious example of unnecessary tests, because the results are misleading, came from 14 laboratories testing against mandelamine. The action of this drug is due to formalin released in urine of suitable $p \mathrm{H}$, and sensitivity tests are totally unreliable (Waterworth, 1962). It may be useful to remind the clinician that treatment with mandelamine might work when the organism is highly resistant to other drugs, but this can be done for coliforms in urine, other than Proteus, by adding a note at the end of the report.

Some laboratories tested mixtures of drugs on the same disc. Combined sensitivity tests cannot be done in this way. The zone reading indicates inhibition of the organism by the drug which diffuses through agar most rapidly. If it is resistant to this drug, and sensitive to the other, a slightly smaller zone will be seen. Strains resistant to the less diffusible drug, but sensitive to the other, cannot be recognized, and no estimate of combined activity can be given.

Some laboratories tested a whole range of sulphonamide drugs and tetracyclines, which is unnecessary. Minor differences in activity cannot be demonstrated by this kind of test, and in any case are of very doubtful value when related to the action of the drug at the site of infection.

\section{REFERENCE}

Waterworth, P. M. (1962). J. med. Lab. Technol., 19, 163. 